\title{
Anti-diabetic effects of fenugreek (Trigonella foenum-graecum): A comparison between oral and intraperitoneal administration - an animal study
}

\author{
MARINE E. BASET ${ }^{1 *}$, TASNEEM I. ALI ${ }^{1 *}$, HANAN ELSHAMY $^{1 *}$, AHMED M. EL SADEK $^{1}$, \\ DIANA G. SAMI ${ }^{2}$, MARWA T. BADAWY ${ }^{2}$, SARA S.ABOU-ZEKRY ${ }^{2}$, HANA H. HEIBA ${ }^{2}$, \\ MONA K. SAADELDIN ${ }^{1,3}$ and AHMED ABDELLATIF ${ }^{2}$ \\ ${ }^{1}$ Faculty of Biotechnology, October University for Modern Sciences and Arts, 6th October City 12573; \\ ${ }^{2}$ Department of Biology, School of Sciences and Engineering, American University in Cairo, New Cairo 11835, Egypt; \\ ${ }^{3}$ Department of Experimental Oncology, European Institute of Oncology, 20139 Milan, Italy
}

Received April 15, 2020; Accepted May 6, 2020

DOI: $10.3892 /$ ijfn.2020.2

\begin{abstract}
Herbal medicine is used by millions of diabetic patients due to economic and cultural factors. The current study investigates the antidiabetic potential of fenugreek (Trigonella foenum-graecum) seed extract at a dose of $100 \mathrm{mg} / \mathrm{kg}$ in a Streptozocin-induced diabetic model. Male Sprague-Dawley rats received either intraperitoneal fenugreek [daily (ED) or every other day (EOD)] or oral fenugreek supplement daily, for four weeks. Results show that fenugreek significantly reduced blood glucose. Urea levels were reduced after daily intraperitoneal injection, and creatinine levels dropped after oral treatment, respectively. AST and ALT levels were reduced following fenugreek treatment, while protein levels significantly increased. High-density lipoprotein (HDL) increased after daily injections, while triglycerides decreased significantly in all groups. Glutathione S-transferase and catalase increased with treatment, while peroxidase antioxidant enzyme levels were reduced. Glutathione peroxidase levels increased only after daily injection. Histologically, fenugreek mildly protected hepatic, renal, and pancreatic tissues. In conclusion, the current study shows some potential benefits of fenugreek use. Oral and injectable fenugreek showed improvement in blood glucose, renal and liver functions. Although triglyceride levels decreased
\end{abstract}

Correspondence to: Dr Ahmed Abdellatif, Department of Biology, School of Sciences and Engineering, The American University in Cairo, New Cairo 11835, Egypt

E-mail: ahmed.abdellatif@aucegypt.edu

Dr Mona K. Saadeldin, Department of Experimental Oncology, European Institute of Oncology, 20139 Milan, Italy

E-mail:m.kamal@aucegypt.edu

*Contributed equally

Key words: Trigonella foenum, oral fenugreek, diabetes, antioxidants, liver, kidney, pancreas significantly, no significant changes in cholesterol levels were seen after fenugreek use. Higher doses and longer fenugreek treatment duration are recommended for the optimum protection of the liver, kidneys, and pancreatic tissues.

\section{Introduction}

Diabetes is a metabolic disorder characterized by hyperglycemia resulting from abnormalities in insulin secretion and action (1). Chronic hyperglycemia leads to microvascular (e.g. neuropathy, and nephropathy) and macrovascular (mainly cardiovascular) complications that arise due to the increased reactive oxygen species production and reduced antioxidants (2).

Herbal products have been widely used throughout history for the treatment of several diseases. Since the characterization and exact mechanisms of action of these natural products remain unclear, researchers are trying to evaluate their beneficial effects on human health as well as their possible adverse effects (3). Despite the presence of several treatments for diabetes such as insulin analogs, sulphonylureas, biguanides, dipeptidyl peptidase- 4 inhibitors, thiazolidine, and $\alpha$-glucosidase inhibitors, patients prefer to use botanicals due to the increased cost and side effects of these medications (2).

Many plants, such as cinnamon and ginseng reduce glucose and lipid levels through the stimulation of insulin secretion, delay of gastric emptying, inhibiting glucosidase activity, increasing GLUT4 expression (4), and the activation of AMP-activated protein pathway (5), and inhibiting gluconeogenesis (6). Several medicinal plants are used for the treatment of diabetes, such as ginger, garlic, fenugreek and cumin $(7,8)$.

Fenugreek (Trigonella foenum-graecum), is a historically used herbal medicinal plant that is popular in Africa, India, South, and Central Asia (9). It is traditionally used to treat several conditions, such as diabetes and obesity. It possesses antioxidant, antihyperlipidemic, antibacterial, antifungal, antiinflammatory, and galactagogic properties (10).

Fenugreek's pharmacological effects are attributed to a range of bioactive compounds such as polyphenols, steroids, lipids, alkaloids, saponins, flavonoids, hydrocarbons, carbohydrates, 
galactomannan fiber, and amino acids. Several scientific groups examined its antidiabetic effect. A previous study showed that fenugreek increased glucose uptake in HepG2 cells is due to the overexpression of the glucose transporter (GLUT-2) (12) and sterol regulatory element-binding protein (SREBP1C) mRNA levels (11). Another report by Pradeep and Srinivasan (13), demonstrated that when combined with $3 \%$ onion, better fenugreek antidiabetic results were seen. A potential fenugreekbased drug $\left(\right.$ Fenfuro $\left.^{\circledR}\right)$ was compared to Metformin in a clinical trial. Results showed that Fenfuro combined with Metformin gave better results than Metformin alone (14).

Diosgenin saponin is considered the most bioactive substance of fenugreek. It has antioxidative effects and plays a pivotal role in improving the diabetic status by several mechanisms $(1,15)$. The mechanisms include $\beta$-cell renewal and insulin secretion stimulation. Besides, diosgenin elevates the mRNA transcription levels of CCAAT/enhancer-binding protein $(\mathrm{C} / \mathrm{EBP} \delta)$ and peroxisome proliferator-activated receptor- $\gamma($ PPAR- $\gamma)(10,12)$.

Other components in fenugreek include; 4-hydroxyisoleucine, which is an amino acid that enhances insulin secretion, decrease plasma triglycerides, and total cholesterol levels (1). Galactomannan is a carbohydrate that represents $45-60 \%$ of the seed of fenugreek. It has been shown to block the carbohydrate and lipid hydrolyzing enzymes in the digestive system, resulting in lowering the postprandial glucose level (1).

Although the detailed mechanisms of action of the fenugreek antidiabetic activity are yet to be identified, many studies suggest that antioxidant activity plays a significant role in hepatoprotection. Another possibility would be that fenugreek reverses protein glycation caused by hyperglycemia (16). Further investigations into the molecular mechanisms of actions and active components of the plant are needed.

In many parts of the world, fenugreek is commonly consumed as a drink. In the current study, we attempt to compare different routes of administration of fenugreek at a clinically feasible dose $(100 \mathrm{mg} / \mathrm{kg})$ in a diabetic rat model induced by streptozocin (STZ).

\section{Materials and methods}

Animals. All experiments were conducted in compliance with the guidelines established by the NIH for Animal Care and Use and were approved by the Institutional Animal Care and Use Committee (IACUC) of the October University for Modern Sciences and Arts (2018). Male Sprague Dawley rats weighing (175-200 g), were obtained from Theodore Bilarz Research Institute (Cairo, Egypt). Rats were randomly divided into the following groups: Group 1: diabetic (DM) rats receiving $100 \mathrm{mg} / \mathrm{kg}$ every other day (EOD) of fenugreek extract (HERBPHARM). Group 2: DM rats receiving daily (ED) fenugreek $100 \mathrm{mg} / \mathrm{kg}$ IP. Group 3: DM rats receiving oral fenugreek $100 \mathrm{mg} / \mathrm{kg}$ daily. Group 4: untreated diabetic group. Group 5: healthy nondiabetic rat group.

Diabetes model. Animals received Streptozocin (STZ; $75 \mathrm{mg} / \mathrm{kg}$ in sterile citrate buffer) intraperitoneally. Diabetes was confirmed one week following STZ injection, by blood glucose levels. Rats showing fasting glucose levels at or above $270 \mathrm{mg} / \mathrm{dl}$ (>15 mmol/l) were included in the study (3). At the

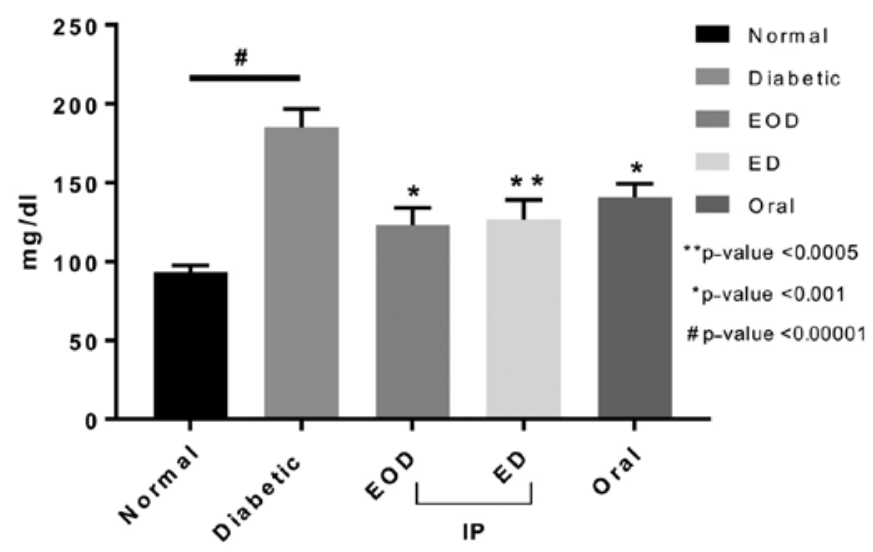

Figure 1. Effect of fenugreek treatment on blood glucose levels in different groups. All groups showed a significant decrease in glucose levels compared to diabetic rats.

end of the experiment, the histological examination of the rat pancreatic tissues confirmed DM.

Sample collection. At the end of the 4 weeks of treatment, rats were anesthetized by ketamine/xylazine (ketamine $80-100 \mathrm{mg} /$ $\mathrm{kg}$, xylazine $10-12.5 \mathrm{mg} / \mathrm{kg}$ IP). Blood was collected by cardiac puncture, and rats were dissected and tissue samples (pancreas, kidney and liver) were collected for biochemical and histological analysis. There was no sample size difference; animals were added to replace lost animals due to mortality.

Biochemical analysis. The collected serum was divided into aliquots to assess the liver, and kidney functions as well as serum glucose and the lipid profile, as previously described (3).

Antioxidant activity assays. Frozen liver tissue samples $(0.2 \mathrm{~g})$ were homogenized in phosphate-buffered saline. The suspension was centrifuged at $4400 \mathrm{rpm}$, and the supernatants collected and tested for the antioxidant enzyme levels.

Catalase enzyme activity. Catalase enzyme activity was measured according to the method originally described by Aebi (17). Briefly, the assay is based on catalase reaction with a known quantity of hydrogen peroxide $\left(\mathrm{H}_{2} \mathrm{O}_{2}\right)$, and the reaction is stopped after $1 \mathrm{~min}$ by a catalase inhibitor. The remaining $\mathrm{H}_{2} \mathrm{O}_{2}$ reacts with 4-aminophenazone and 3,5-dichloro-2hydroxy-benzene sulfonic acid to form a chromophore. The absorbance is measured at $510 \mathrm{~nm}$ using a spectrophotometer.

Glutathione peroxidase. Glutathione peroxidase was measured based on the method described initially by Paglia and Valentine (18). The assay principle is based on the indirect measurement of the activity of cellular glutathione peroxidase enzyme. Oxidized glutathione (GSSG) is produced by reduction of an organic peroxide by cellular glutathione. The rate of decrease in the absorbance at 340 is directly proportional to the glutathione peroxidase activity in the sample.

Glutathione S-transferase (GST) enzymatic activity. The measured enzyme activity is based on the method designed by Habig et al (19). The action of GST enzyme is to catalyze the 

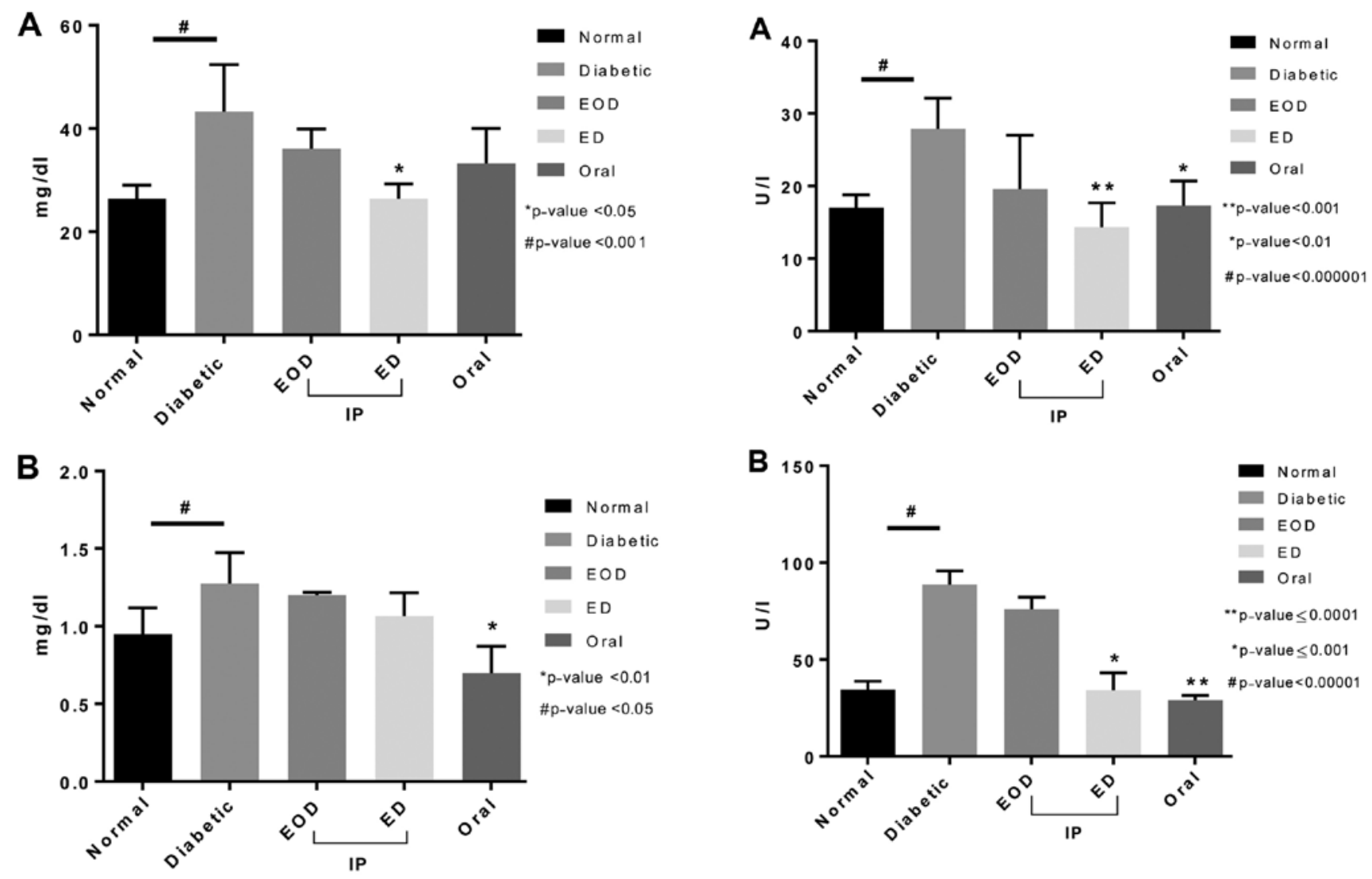

Figure 2. Effect of fenugreek treatment on kidney function: (A) Urea level significantly increased in diabetic rats compared to the normal group. ED injection group was the only one to show a significant decrease compared to diabetic rats, which was back to normal. (B) Creatinine levels were increased in diabetic rats. Oral treatment showed a significant reduction in creatinine levels compared to diabetic rats. Data are shown as mean $\pm S D, n=5$.

conjugation of reduced glutathione (GSH) with 1-chloro 2,4-dinitrobenzene $(\mathrm{CDNB})$ via the $-\mathrm{SH}$ group of glutathione. This results in the production of the conjugate, S-(2,4-dinitrophenyl)L-glutathione, which can be detected. The absorbance is read at $340 \mathrm{~nm}$.

Peroxidase activity. Peroxidase activity is based on the enzyme inhibition (20) by the addition of sulfite so that it is inactive when the hydrogen peroxide is added. Freshly prepared $1 \%$ o-phenylenediamine and $0.3 \%$ hydrogen peroxide are added to liver tissue homogenate. The reaction is stopped after $5 \mathrm{~min}$ by adding sodium bisulfite. The absorbance was measured at $430 \mathrm{~nm}$. The enzyme activity is expressed as the change in absorbance at $430 \mathrm{~nm}(\Delta \mathrm{OD} 430) / \mathrm{min} / \mathrm{mg}$ protein.

Histological analysis. Formaldehyde fixed tissue samples were paraffin-embedded, and $5 \mu \mathrm{m}$ sections were cut and stained with hematoxylin and eosin. Slides were examined and photographed using a BX51 light microscope with an Olympus digital camera (DP20) (Olympus).

Statistical analysis. The statistical analyses were performed using GraphPad Prism software, version 7.04 (GraphPad, Inc.). Data are presented as mean \pm standard deviation. One-way ANOVA and Tukey test were used. $\mathrm{P}<0.05$ was considered to indicate a statistically significant difference.

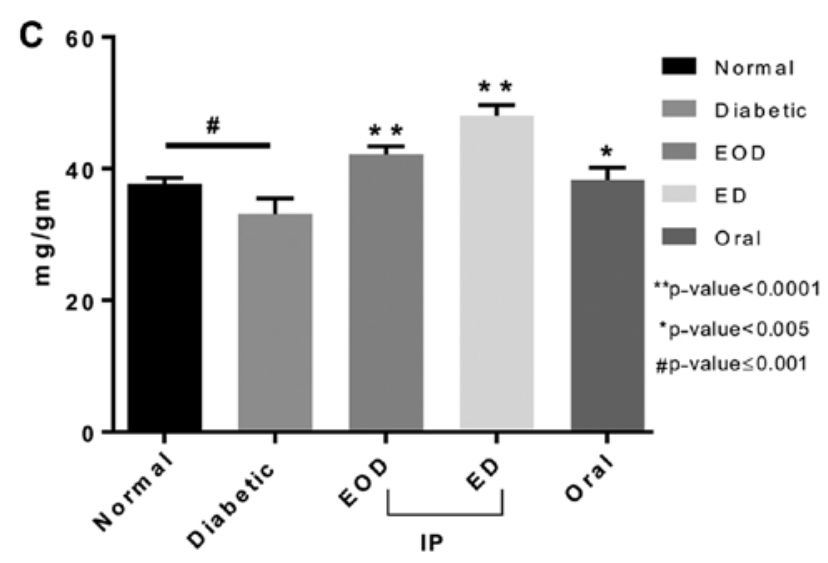

Figure 3. Effect of fenugreek treatment on liver function test: Liver enzymes (A) Aspartate aminotransferase (AST) and (B) Alanine aminotransferase (ALT) levels increased in diabetic rats. Oral and ED injection groups showed a significant decrease in both AST and ALT levels compared to diabetic rats. (C) On protein levels, fenugreek administration caused a significant increase in protein levels in all treated groups compared to untreated diabetic rats. Data are shown as mean $\pm S D, n=5$. $E D$, daily.

\section{Results}

Blood glucose levels. Fasting blood glucose levels of rats treated with fenugreek extract were significantly reduced after treatment compared to the diabetic control group in all treated groups (Fig. 1). There was no significant difference between treatment groups.

Renal function. Urea levels increased in diabetic rats (Fig. 2). No significant reduction was seen after fenugreek treatment except with the daily injection group (Fig. 2). Creatinine levels also increased in untreated DM rats. Fenugreek injection 

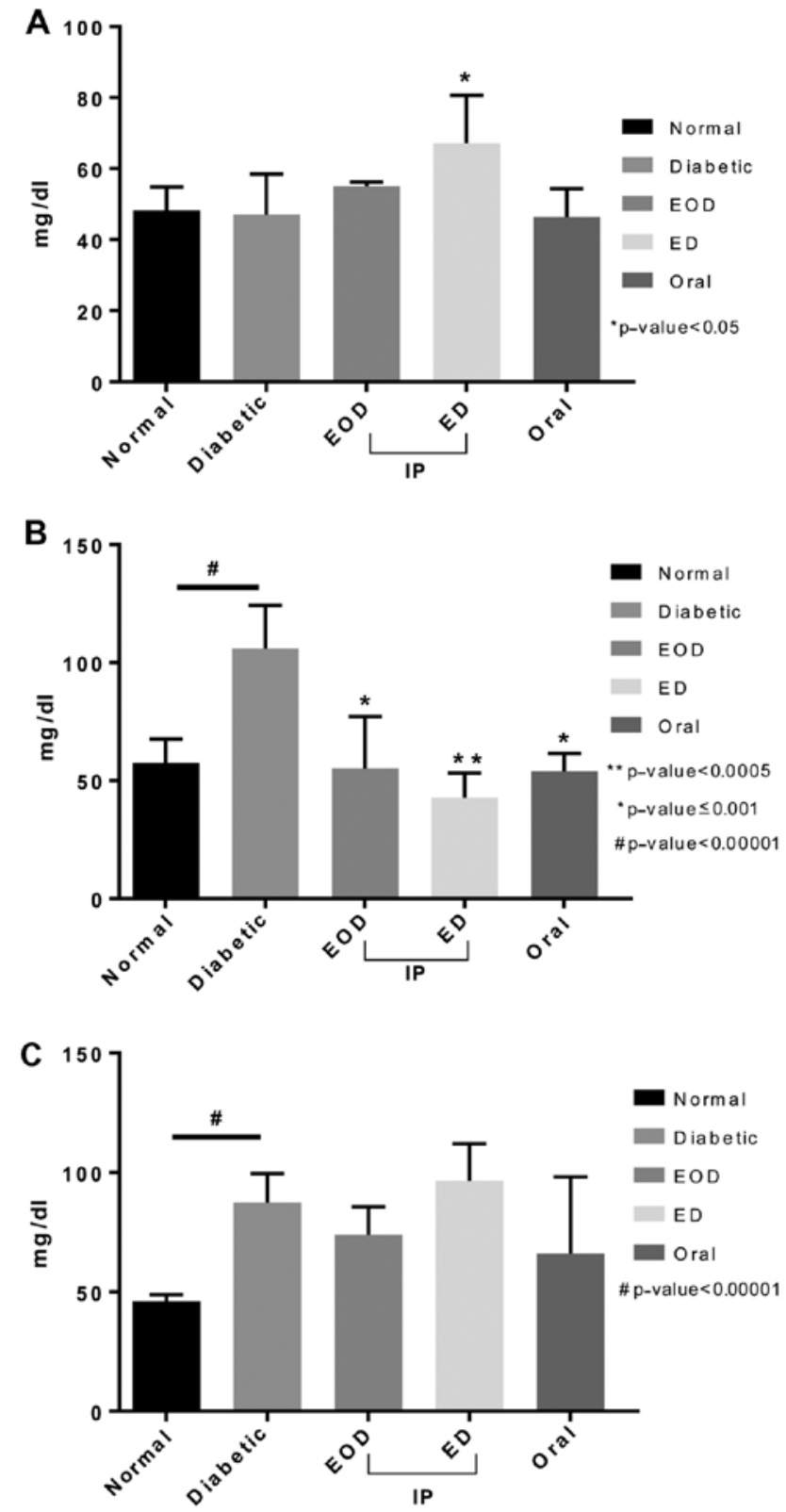

Figure 4. Effect of fenugreek treatment on lipid profile: (A) High-density lipoprotein (HDL). (B) Cholesterol levels were not increased in diabetic rats compared to normal, only after ED injection of fenugreek a significant increase was seen in HDL levels. (C) Triglycerides were significantly increased in diabetic rats. All treatment groups showed a significant decrease in triglycerides. Fenugreek treatment did not cause any significant change in cholesterol levels. Data are shown as mean $\pm S D, n=5$. ED, daily.

did not reduce creatinine levels. Only after oral treatment, a significant decrease in creatinine was seen (Fig. 2).

Liver functions and lipid profile. Alanine aminotransferase (ALT) and aspartate aminotransferase (AST) levels increased in diabetic rats. Fenugreek treatment in both the oral and daily injection (ED) groups significantly decreased both AST and ALT levels compared to the diabetic control group. Protein levels significantly increased in all treated groups compared to untreated diabetic rats. ED injections showed the highest value and significance compared to the diabetic control (Fig. 3).

High-density lipoprotein (HDL) levels did not increase in diabetic rats compared to normal. Only after daily fenugreek
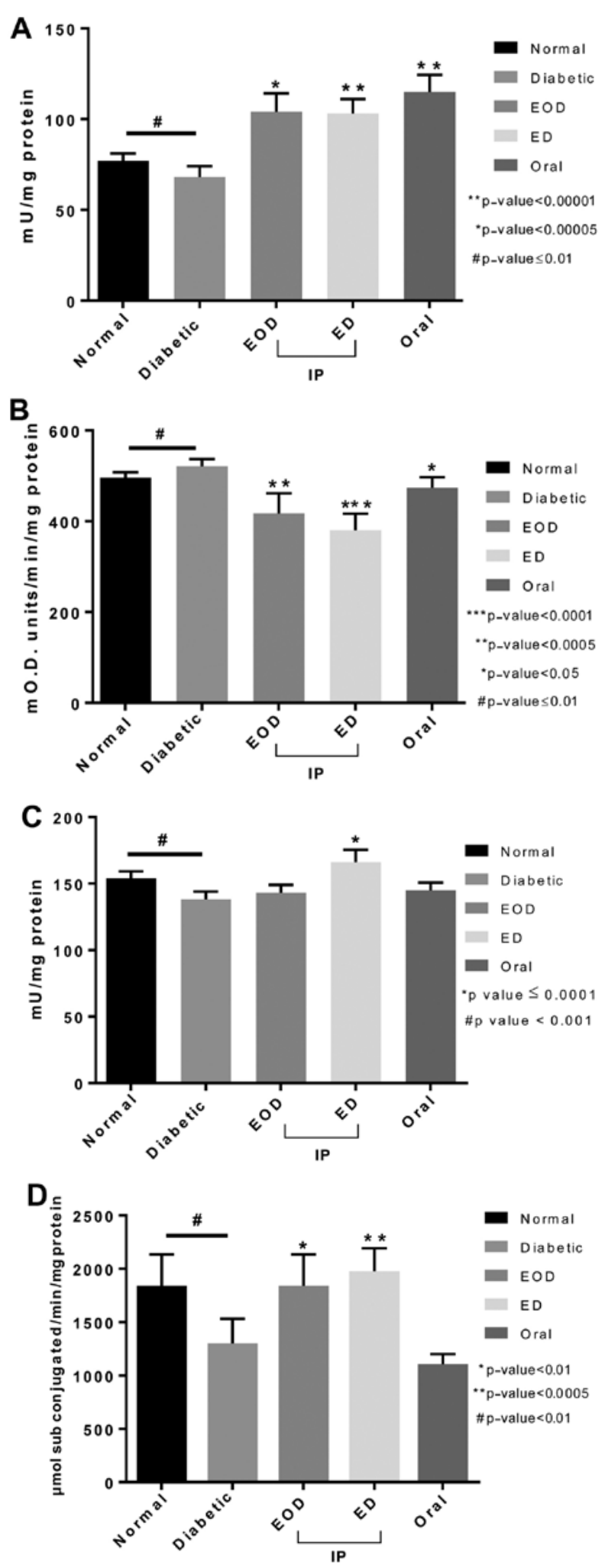

Figure 5. Effect of fenugreek treatment on liver antioxidant enzymes. (A) Catalase enzyme levels were not significantly different between normal and diabetic rats. These levels increased significantly in all treated groups. (B) Peroxidase levels were increased in diabetic rats compared to normal. All treated groups showed a significant reduction in peroxidase levels compared to diabetic untreated rats. (C) Glutathione peroxidase levels were not changed in diabetic untreated or EOD and oral treated rats. The only group showing a significant increase was the ED injection treated group. (D) Glutathione S-transferase enzyme was significantly reduced in diabetic untreated rats. No significant change was seen with the oral administration of fenugreek, whereas both EOD and ED injected groups showed a significant increase in the enzyme levels compared to the diabetic control group. Data are shown as mean $\pm \mathrm{SD}$, $\mathrm{n}=5$. ED, daily, EOD, every other day. 

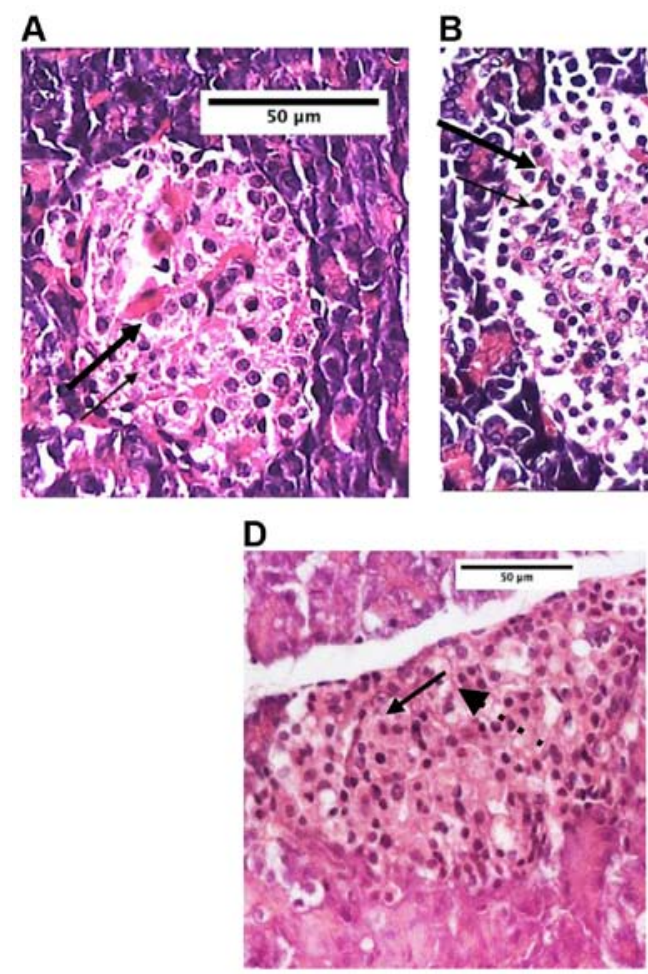
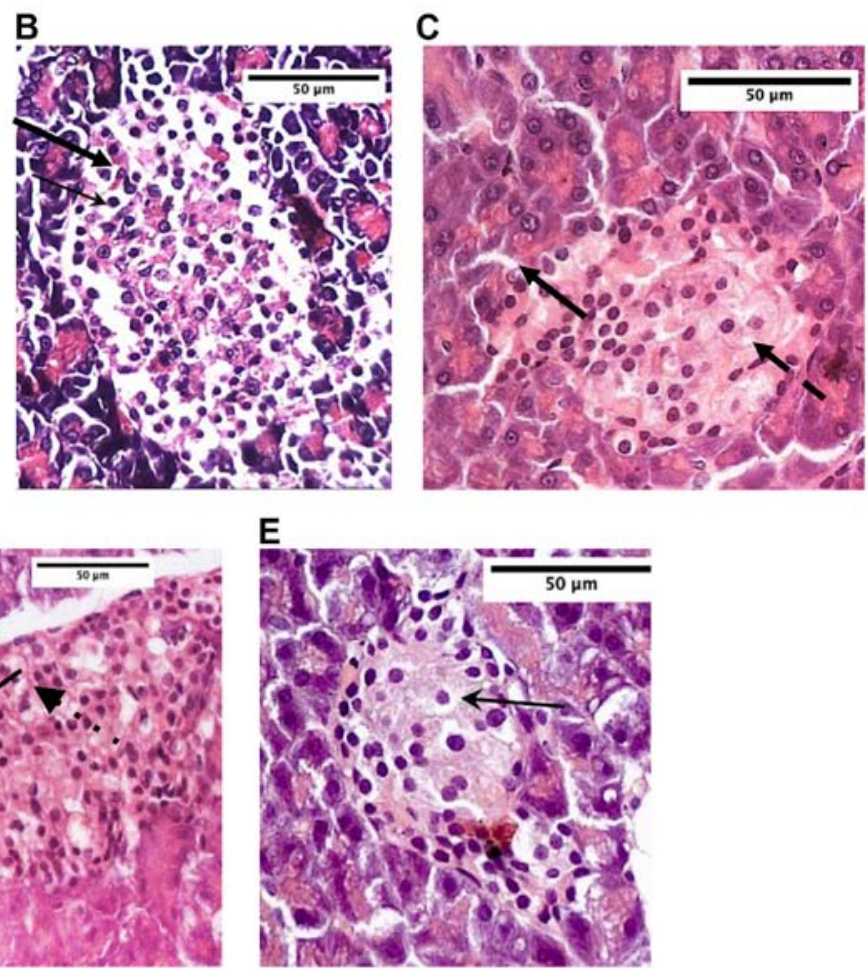

Figure 6. Histological changes in the pancreas. (A) Normal samples showed normal histological structures of endocrine cells of pancreatic islets without abnormal alterations. (B) Diabetic rats showed severe degenerative and vacuolar changes of the outer cellular zone of pancreatic islets with karyo-pyknosis of most of the cells (arrow). (C) Animals receiving oral fenugreek showed no protective effects and degenerative changes in cellular elements of pancreatic islets with many cells demonstrating pyknotic nuclei (arrow) with variable records of cytoplasmic vacuolation (dashed arrow). (D) Every other day injection of fenugreek showed deterioration changes in cellular components of pancreatic islets in most of the tissue sections with numerous cells demonstrating pyknotic nuclei (arrow). The dashed arrow shows irregular records of cytoplasmic vacuolation. The pancreas shows mild degenerative changes in cellular components of pancreatic islets in most of the tissue sections with numerous cells demonstrating pyknotic nuclei. The dashed arrow shows irregular records of cytoplasmic vacuolation. (E) Every day injection of fenugreek showed mild pyknosis with cytoplasmic vacuolar changes (arrow). (arrow) (n=4).

injection, a significant increase was seen. Triglycerides, on the other hand, significantly increased in diabetic rats. All treatment groups showed a significant decrease in triglyceride levels compared to diabetic rats injected daily, which showed the highest significance. Cholesterol levels increased following induction of diabetic and were not decreased after fenugreek treatment (Fig. 4).

Antioxidant enzymes. Catalase enzyme in the liver tissue of untreated diabetic rats was slightly lower compared to the normal rats. Catalase levels increased significantly in all treatment groups compared to both normal and untreated diabetic rats, with oral fenugreek showing the highest levels (Fig. 5A). Quantitative determination of peroxidase activity in liver tissue showed that the peroxidase antioxidant enzyme levels were increased in diabetic rats compared to normal. All treated groups showed a significant reduction in peroxidase levels compared to diabetic untreated rats. The daily injection group showed the highest and most significant reduction (Fig. 5B).

Glutathione peroxidase levels were changed slightly in diabetic untreated rats. Only following daily injections, there was a significant increase in glutathione peroxidase levels (Fig. 5C). Glutathione s-transferase enzyme was significantly reduced in untreated diabetic rats. Both EOD and daily injections treated groups showed a significant increase in the enzyme levels compared to the diabetic group with the daily injection group significantly higher than the EOD injection group (Fig. 5D).

Histological changes in the pancreas. Normal rats showed a typical healthy architecture of the pancreatic islets of Langerhans, with no signs of cell injury observed. Untreated DM rats showed severe alteration in both the acini and islets of the pancreas, most of the cell nuclei were thickened and appeared larger, indicating karyo-pyknosis of the cells; also, numerous vacuoles were observed (Fig. 6A and B).

In rats receiving oral fenugreek extract, the pancreas showed no signs of protection, with destructive and degenerative changes in the pancreatic islets in almost all tissue sections, with many cells demonstrating pyknotic nuclei with variable records of cytoplasmic vacuolation (Fig. 6C). Treatment with fenugreek injections (ED and EOD) (Fig. 6D and E) showed no histological signs of improvement with changes in cellular components of pancreatic islets with numerous cells demonstrating pyknotic nuclei, and cytoplasmic vacuolation.

Histological changes in the kidneys. Normal rats demonstrated normal histological features of the renal cortex and medulla with intact corpuscles, while diabetic rats showed wide areas of damage with intraluminal cast formation and many degenerated tubular cells and congested inter-tubular blood vessels. (Fig. 7A and B). Oral fenugreek extract showed focal areas of degenerative vacuolar changes in lining cells 


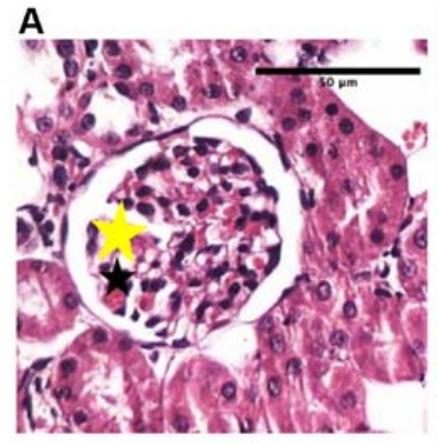

D

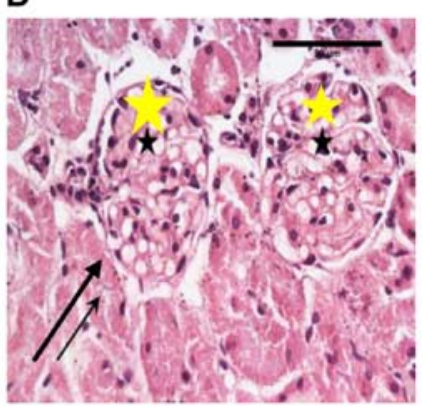

B

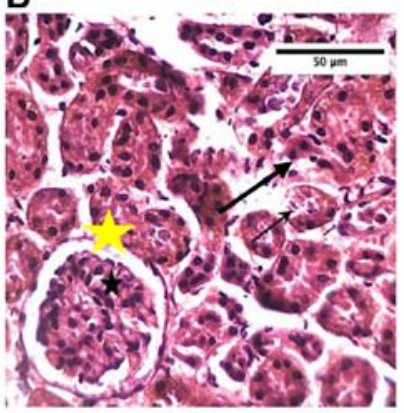

C

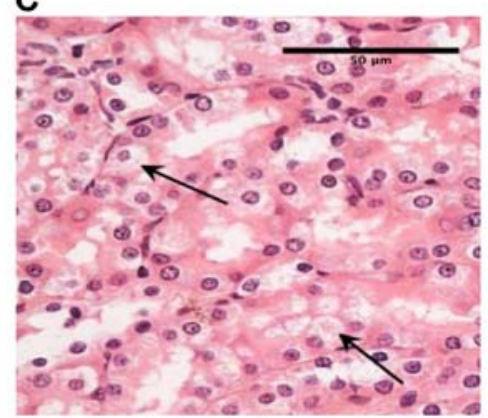

$\mathrm{E}$

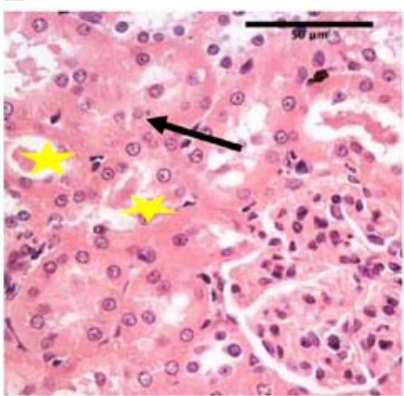

Figure 7. Histological changes in the kidneys. (A) Samples demonstrated the normal histological features of the renal cortex and medulla with intact renal corpuscles (star) and different tubular structures in different regions. (B) Diabetic samples showed wide areas with intraluminal cast formation in different segments of nephrons (star) with many degenerated tubular cells (arrow) and congested inter-tubular blood vessels (arrowhead). (C) Oral fenugreek samples showed focal areas of degenerative vacuolar changes in lining cells and/or pyknotic nuclei (arrow). (D) Every other day injections showed more pronounced damage of renal corpuscles with severe vacuolar changes in mesangial cells accompanied with hypocellularity (star). Severe necrobiotic changes were recorded in tubular lining cells. Most of the cells losing the cellular details (arrow). (E) Every day injection showed intraluminal eosinophilic casts (star) and mild necrobiotic changes (arrow).

A

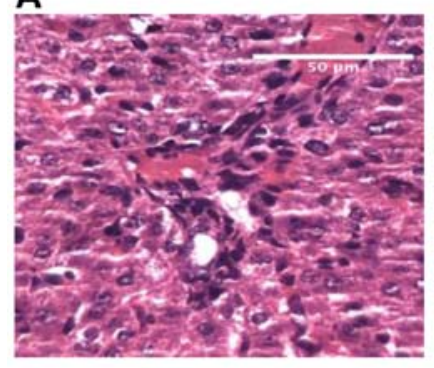

D

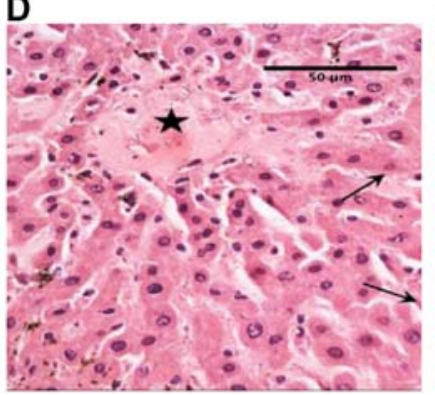

B

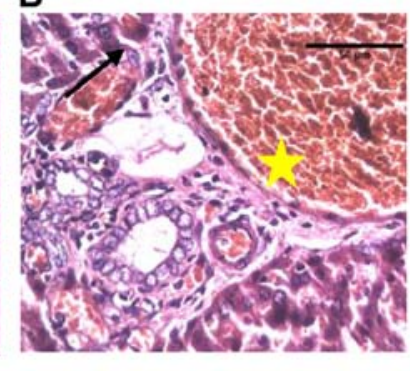

C

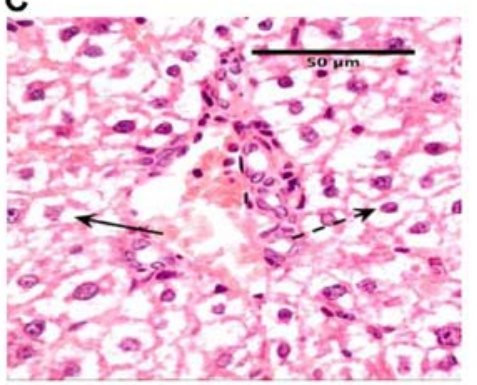

E

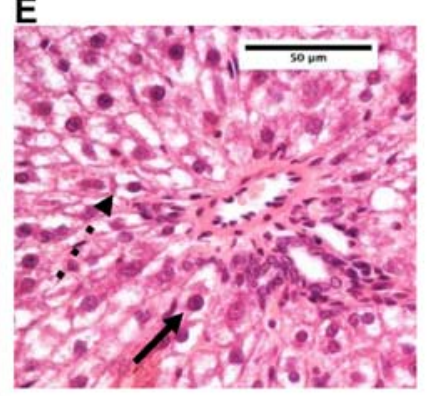

Figure 8. Histological changes in the liver tissues. (A) Control samples showed apparent normal hepatic tissue with normal appearance of hepatocytes, blood vessels, and sinusoids. (B) Diabetic rats showed dilatated and congested blood vessels (star) and sinusoids with high number of degenerating hepatocytes with karyo-pyknosis (arrow). (C) Oral fenugreek samples showed diffuse vacuolar degeneration of hepatocytes (arrow) with numerous shrunken pyknotic nuclei (dashed arrow). (D) Every other day treatment showed hepatocytes with many cells showing pyknotic nuclei (arrow) and more extensive congestion of the sinusoids (star). (E) Every day fenugreek injection demonstrated extensive degeneration of hepatocytes (arrow) with shrunken pyknotic nuclei (dashed arrow).

and or pyknotic nuclei (Fig. 7C). Fenugreek injections showed pronounced damage of renal corpuscles, severe vacuolar changes in mesangial cells, and severe necrotic changes in tubular lining cells, with most cells losing cellular details (Fig. 7D and E).
Histological changes in the liver. Hepatic tissue samples from normal rats showed normal hepatocytes, blood vessels, and sinusoids, as shown in Fig. 8A. Untreated diabetic rats showed high numbers of degenerated hepatocytes with karyopyknosis, and dilatation and congestion of blood vessels and 
sinusoids (Fig. 8B). Oral fenugreek extract treatment showed degenerating hepatocytes with shrunken pyknotic nuclei and missing cellular details (Fig. 8C). Fenugreek injections showed degenerating hepatocytes with shrunken pyknotic nuclei and loss of cellular details (Fig. 8D and E).

\section{Discussion}

In the current study, we used an STZ model to compare different routes of administration of fenugreek (10). STZ have been used extensively in diabetes research especially for the study of various therapeutic approaches, including the use of plant extracts as supplements in diabetes care (21-23).

Fenugreek is a plant widely consumed in different parts of the world. Here we provide a comprehensive evaluation of fenugreek seed extract treatment on the pancreas, liver, and kidneys both biochemically and histologically. Induction of diabetes was confirmed biochemically with elevated blood glucose levels, as well as histologically with islets of the pancreas showing signs of destruction on histological examination.

We attempted to test glycosylated hemoglobin (HbAlc); unfortunately, the results obtained were unreliable (data not shown). This might be due to the difficulty of measuring HbA1C in Sprague-Dawley rats, as reported by other researchers $(24,25)$. Some researchers suggest that $\mathrm{HbA1C}$ should be estimated using other tools such as ELISA, or highperformance liquid chromatography (HPLC) (26).

Fenugreek seed extract administration reduced blood glucose levels, possibly due to the high content of alkaloid trigonelline and steroidal saponins in fenugreek, especially the 4-hydroxyisoleucine compound that is said to be insulinotropic (27). The current data confirm previous reports (28) that showed a dose of $50 \mathrm{mg} / \mathrm{kg}$ of orally administered fenugreek for 4 weeks in STZ diabetic rabbits, produced similar effects.

The architecture of the pancreatic tissue correlates with the stage of diabetes and its severity (29). In the current study after STZ injection, diabetic rats showed damage to the pancreatic islet cells and severe pathological changes to exocrine and endocrine components, which is consistent with previous findings (30). Rats treated with fenugreek, showed protection of pancreatic tissues, possibly due to the presence of diosgenin which is postulated to have several antidiabetic effects, such as the regeneration of pancreatic $\beta$-cells and enhancement of insulin secretion in general $(1,31)$. Diosgenin also improved blood glucose levels maintenance and preserved the pancreas, liver, and skeletal muscle tissues (1). Previous report (32) on the effects of fenugreek oil on the pancreas in an Alloxan induced diabetic rat model showed that pancreatic cell damage and renal function were slightly reversed after treatment with fenugreek oil.

Oral fenugreek showed a significant decrease in creatinine levels, in contrast to EOD and ED injections. This is consistent with previous reports (33), showing improved renal functions with fenugreek administration. Histologically better protection was achieved (33), possibly due to the longer treatment period. Other researchers also reported improvement in creatinine levels and improvement of the glomerular base membrane in the kidneys of diabetic rats when fenugreek extract was administered orally. These findings also support the present study and show the potential of fenugreek as a drug for diabetes and its renal complications $(34,35)$.
Recent metabolomics studies on the effect of fenugreek flavonoids on STZ showed a significant impact on liver, kidney, and pancreas $(36,37)$. The fenugreek flavonoids lowered insulin resistance, improved glycolysis, and gluconeogenesis, and protected kidneys and pancreatic islet cells from damage.

Serum levels of liver enzymes (ALT and AST) increased in untreated diabetic rats and were significantly reduced compared to diabetic rats after fenugreek treatment. This high serum level is attributed to the injuries to the liver cells (38). Fenugreek caused a significant reduction in the liver enzyme levels, indicating a protective effect of liver cells. These findings are consistent with previous data that showed a protective effect of fenugreek as a daily supplement (39-42). Other studies reported that treatment with fenugreek aqueous seed extract (43), using a dose of $25 \mathrm{mg} / \mathrm{kg}$ body weight for 60 days, significantly decreased blood glucose and liver enzyme levels. However, no histological liver protective role was reported.

The effects of fenugreek seed extract on lipid profile in the current study showed a significant reduction in triglyceride levels compared to diabetic rats. However, a significant increase in HDL levels was demonstrated only after daily injections, compared to diabetic rats, unlike other treatment groups which did not show a substantial increase in HDL levels. This suggests a better effect after the daily (ED) injection. No effects on total cholesterol levels were observed in any of the treatment groups. Cholesterol findings are somewhat in disagreement with previous reports (44), where a dose of $500 \mathrm{mg} / \mathrm{kg}$ for four weeks caused improvement in lipid profile (HDL, cholesterol, and triglycerides). This difference might be due to the lower dose used in the current study $(100 \mathrm{mg} / \mathrm{kg})$.

Catalase and glutathione-S-transferase (GST) enzymes are crucial anti-oxidative enzymes in the liver. Our results show that fenugreek treatment led to a significant increase in GST enzyme levels in EOD and ED injection groups when compared to diabetic rats, unlike the oral route, which did not show significance. Concerning catalase, a significant increase in the enzyme levels was observed in all groups compared to diabetic rats. This indicates considerable potential for fenugreek as a booster for antioxidant activity in the liver due to its high content of diosgenin (1,31). Previous studies showed similar results, therefore, confirming the antioxidant effect of fenugreek (45).

There was a significant increase in peroxidase activity within the liver tissue of untreated diabetic rats compared to healthy rats. This might be due to the high oxidative stress exerted on the liver tissue due to the induction of diabetes by STZ or as a complication of hyperglycemia (46). In all treated groups, there was a significant reduction in peroxidase activity compared to diabetic rats.

Glutathione peroxidase levels were unchanged in the present study except for the ED injection treated rats where a significant increase was observed compared to normal and diabetic rats. This suggests a better effect in this group (ED injection) over other groups (EOD injection and oral).

In the current study, a reduction in total proteins in the untreated diabetic group was reversed by fenugreek extract treatment. This increase in protein levels could be attributed to the hyperglycemic effect on the liver tissue, as a result of glycation of the antioxidant enzymes, which eventually leads to alteration and damage in cell structural proteins and enzymes caused by the reactive oxygen species (46). 
Fenugreek may also improve the body's use of sugar, adjusting insulin release, and possibly lowers the absorption of glucose from the intestine (47). Oral intake of fenugreek is also associated with liver protection and a better quality of life for diabetic patients (48). Fenugreek is also useful as a digestive stimulant and has potent antibacterial and oxidant activity (49).

In conclusion, fenugreek daily injection showed better antidiabetic effects with better serum values than other groups. Although in all groups, there was an improvement of the antioxidant enzymes and other diabetic parameters, the histological structure was not fully restored in the kidney, liver or the pancreas. This can be due to the low dose tested and the relatively short test period (one month).

Fenugreek seems to be a promising anti-diabetic plant. Further work is needed to better identify the mechanism of action and the effective dose range. Longer periods are recommended to achieve histological improvement.

\section{Acknowledgments}

Not applicable.

\section{Funding}

This research did not receive any specific grant from funding agencies in the public, commercial, or not-for-profit sectors.

\section{Availability of data and materials}

The datasets used during the present study are available from the corresponding author upon reasonable request.

\section{Authors' contributions}

MEB, TIA and HE were involved in data investigation and data curation. AMES was involved in data curation, and in the writing of the original draft. DGS, MTB, SSAZ and HHH were involved in data analysis and validation, and in the writing, reviewing and editing of the manuscript. MKS and AA were involved in the conceptualization, methodology, supervision, validation of the study, and in the reviewing and editing of the manuscript. All authors read and approved the manuscript and agree to be accountable for all aspects of the research in ensuring that the accuracy or integrity of any part of the work are appropriately investigated and resolved.

\section{Ethics approval and consent to participate}

This study was approved by the Institutional Animal Care and Use Committee (IACUC) of the October University for Modern Sciences and Arts (2018).

\section{Patient consent for publication}

Not applicable.

\section{Competing interests}

The authors declare that they have no competing interests.

\section{Authors' information}

The Orcid ID numbers for the following authors are: MTB, orcid.org/0000-0002-8570-7739; SSAZ, orcid.org/0000-00016069-8760; AA, orcid.org/0000-0003-0486-348X; MKS, orcid. org/0000-0002-2072-0975; AMES, orcid.org/0000-0002-51691214.

\section{References}

1. Ota A and Ulrih NP: An overview of herbal products and secondary metabolites used for management of type two diabetes. Front Pharmacol 8: 436, 2017.

2. Choudhury H, Pandey M, Hua CK, Mun CS, Jing JK, Kong L, Ern LY, Ashraf NA, Kit SW, Yee TS, et al: An update on natural compounds in the remedy of diabetes mellitus: A systematic review. J Tradit Complement Med 8: 361-376, 2017.

3. Essa R, El Sadek AM, Baset ME, Rawash MA, Sami DG, Badawy MT, Mansour ME, Attia H, Saadeldin MK and Abdellatif A: Effects of turmeric (Curcuma longa) extract in streptozocin-induced diabetic model. J Food Biochem 43: e12988, 2019.

4. Bi X, Lim J and Henry CJ: Spices in the management of diabetes mellitus. Food Chem 217: 281-293, 2017.

5. Governa P, Baini G, Borgonetti V, Cettolin G, Giachetti D, Magnano AR, Miraldi E and Biagi M: Phytotherapy in the management of diabetes: A Review. Molecules 23: E105, 2018.

6. Adam SH, Giribabu N, Kassim N, Kumar KE, Brahmayya M, Arya A and Salleh N: Protective effect of aqueous seed extract of Vitis Vinifera against oxidative stress, inflammation and apoptosis in the pancreas of adult male rats with diabetes mellitus. Biomed Pharmacother 81: 439-452, 2016.

7. Deng R: A review of the hypoglycemic effects of five commonly used herbal food supplements. Recent Pat Food Nutr Agric 4: 50-60, 2012.

8. Medagama $\mathrm{AB}$ and Bandara R: The use of complementary and alternative medicines (CAMs) in the treatment of diabetes mellitus: Is continued use safe and effective? Nutr J 13: 102, 2014.

9. Basch E, Ulbricht C, Kuo G, Szapary P and Smith M: Therapeutic applications of fenugreek. Altern Med Rev 8: 20-27, 2003.

10. Nagulapalli Venkata KC, Swaroop A, Bagchi D and Bishayee A: A small plant with big benefits: Fenugreek (Trigonella foenumgraecum Linn.) for disease prevention and health promotion. Mol Nutr Food Res 61: 1600950, 2017.

11. Naicker N, Nagiah S, Phulukdaree A and Chuturgoon A: Trigonella foenum-graecum seed extract, 4-hydroxyisoleucine, and metformin stimulate proximal insulin signaling and increase expression of glycogenic enzymes and GLUT2 in HepG2 cells. Metab Syndr Relat Disord 14: 114-120, 2016.

12. Kumar A, Aswal S, Chauhan A, Semwal RB, Kumar A and Semwal DK: Ethnomedicinal investigation of medicinal plants of Chakrata region (Uttarakhand) used in the traditional medicine for diabetes by Jaunsari tribe. Nat Prod Bioprospect 9: 175-200, 2019.

13. Pradeep SR and Srinivasan K: Amelioration of hyperglycemia and associated metabolic abnormalities by a combination of fenugreek (Trigonella foenum-graecum) seeds and onion (Allium cepa) in experimental diabetes. J Basic Clin Physiol Pharmacol 28: 493-505, 2017.

14. Verma N, Usman K, Patel N, Jain A, Dhakre S, Swaroop A, Bagchi M, Kumar P, Preuss HG and Bagchi D: A multicenter clinical study to determine the efficacy of a novel fenugreek seed (Trigonella foenum-graecum) extract $\left(\right.$ Fenfuro $\left.^{\mathrm{TM}}\right)$ in patients with type 2 diabetes. Food Nutr Res 60: 32382, 2016.

15. Tomcik KA, Smiles WJ, Camera DM, Hügel HM, Hawley JA and Watts R: Fenugreek increases insulin-stimulated creatine content in L6C11 muscle myotubes. Eur J Nutr 56: 973-979, 2017.

16. Maritim AC, Sanders RA and Watkins JB III: Effects of alpha-lipoic acid on biomarkers of oxidative stress in streptozotocin-induced diabetic rats. J Nutr Biochem 14: 288-294, 2003.

17. Aebi H: Catalase in vitro. Methods Enzymol 105: 121-126, 1984.

18. Paglia DE and Valentine WN: Studies on the quantitative and qualitative characterization of erythrocyte glutathione peroxidase. J Lab Clin Med 70: 158-169, 1967.

19. Habig WH, Pabst MJ, Fleischner G, Gatmaitan Z, Arias IM and Jakoby WB: The identity of glutathione S-transferase B with ligandin, a major binding protein of liver. Proc Natl Acad Sci USA 71: 3879-3882, 1974. 
20. Vetter HF and Vullers R: Effectiveness of enzyme substitution with pancynorm in chronic gastroduodenitis. Munch Med Wochenschr 100: 1786-1787, 1958 (In German).

21. Szkudelski T: The mechanism of alloxan and streptozotocin action in B cells of the rat pancreas. Physiol Res 50: 537-546, 2001.

22. Lenzen S: The mechanisms of alloxan- and streptozotocininduced diabetes. Diabetologia 51: 216-226, 2008.

23. Ozkol H, Tuluce Y, Dilsiz N and Koyuncu I: Therapeutic potential of some plant extracts used in Turkish traditional medicine on streptozocin-induced type 1 diabetes mellitus in rats. J Membr Biol 246: 47-55, 2013.

24. Little RR and Roberts WL: A review of variant hemoglobins interfering with hemoglobin A1c measurement. J Diabetes Sci Technol 3: 446-451, 2009.

25. Little RR and Sacks DB: HbAlc: How do we measure it and what does it mean? Curr Opin Endocrinol Diabetes Obes 16: 113-118, 2009.

26. Pundir CS and Chawla S: Determination of glycated hemoglobin with special emphasis on biosensing methods. Anal Biochem 444: 47-56, 2014.

27. Haeri MR, Limaki HK, White CJ and White KN: Non-insulin dependent anti-diabetic activity of (2S, 3R, 4S) 4-hydroxyisoleucine of fenugreek (Trigonella foenum graecum) in streptozotocin-induced type I diabetic rats. Phytomedicine 19: 571-574, 2012.

28. Puri D, Prabhu KM and Murthy PS: Mechanism of action of a hypoglycemic principle isolated from fenugreek seeds. Indian J Physiol Pharmacol 46: 457-462, 2002.

29. Murao K, Yu X, Imachi H, Cao WM, Chen K, Matsumoto K, Nishiuchi T, Wong NC and Ishida T: Hyperglycemia suppresses hepatic scavenger receptor class B type I expression. Am J Physiol Endocrinol Metab 294: E78-E87, 2008

30. Noor Mohamad Zin NS, Hashim N, Samsulrizal N and Azmi NS: The protective effect of Azadirachta excelsa leaves extract and quercetin treatment on the learning and memory impairments in relation with insulin and amylin levels in the brain of streptozotocin-induced diabetic rats. J King Saud Univ Sci 31: 299-307, 2019. https://doi.org/10.1016/j.jksus.2018.05.017.

31. Kalailingam P, Kannaian B, Tamilmani E and Kaliaperumal R: Efficacy of natural diosgenin on cardiovascular risk, insulin secretion, and beta cells in streptozotocin (STZ)-induced diabetic rats. Phytomedicine 21: 1154-1161, 2014.

32. Hamden K, Jaouadi B, Carreau S, Aouidet A, El-Fazaa S, Gharbi N and Elfeki A: Potential protective effect on key steroidogenesis and metabolic enzymes and sperm abnormalities by fenugreek steroids in testis and epididymis of surviving diabetic rats. Arch Physiol Biochem 116: 146-155, 2010.

33. Jin Y, Shi Y, Zou Y, Miao C, Sun B and Li C: Fenugreek prevents the development of STZ-induced diabetic nephropathy in a rat model of diabetes. Evid Based Complement Alternat Med 2014 259368, 2014.

34. Xue WL, Li XS, Zhang J, Liu YH, Wang ZL and Zhang RJ: Effect of Trigonella foenum-graecum (fenugreek) extract on blood glucose, blood lipid and hemorheological properties in streptozotocin-induced diabetic rats. Asia Pac J Clin Nutr 16 (Suppl 1): 422-426, 2007.

35. Xue W, Lei J, Li X and Zhang R: Trigonella foenum graecum seed extract protects kidney function and morphology in diabetic rats via its antioxidant activity. Nutr Res 31: 555-562, 2011.
36. Jiang W, Gao L, Li P, Kan H, Qu J, Men L, Liu Z and Liu Z: Metabonomics study of the therapeutic mechanism of fenugreek galactomannan on diabetic hyperglycemia in rats, by ultraperformance liquid chromatography coupled with quadrupole time-of-flight mass spectrometry. J Chromatogr B Analyt Technol Biomed Life Sci 1044-1045: 8-16, 2017.

37. Jiang W, Si L, Li P, Bai B, Qu J, Hou B, Zou H, Fan X, Liu Z, Liu Z, et al: Serum metabonomics study on antidiabetic effects of fenugreek flavonoids in streptozotocin-induced rats. J Chromatogr B Analyt Technol Biomed Life Sci 1092: 466-472, 2018.

38. Brent JA and Rumack BH: Role of free radicals in toxic hepatic injury. II. Are free radicals the cause of toxin-induced liver injury? J Toxicol Clin Toxicol 31: 173-196, 1993.

39. Elmnan A, Balgees A and Mangara JL: Effect of fenugreek (Trigonella foenm greacum) seed dietary levels on lipid profile and body weight gain of rats. Pak J Nutr 11: 1004-1008, 2012.

40. Garcia TS, Rech TH and Leitão CB: Pancreatic volume in diabetes mellitus. Pancreas 46: e51, 2017.

41. Garcia TS, Rech TH and Leitão CB: Pancreatic size and fat content in diabetes: A systematic review and meta-analysis of imaging studies. PLoS One 12: e0180911, 2017.

42. Raju J and Bird RP: Alleviation of hepatic steatosis accompanied by modulation of plasma and liver TNF-alpha levels by Trigonella foenum graecum (fenugreek) seeds in Zucker obese (fa/fa) rats. Int J Obes 30: 1298-1307, 2006.

43. Sushma N and Devasena T: Aqueous extract of Trigonella foenum graecum (fenugreek) prevents cypermethrin-induced hepatotoxicity and nephrotoxicity. Hum Exp Toxicol 29: 311-319, 2010.

44. Sharma MS and Choudhary PR: Hypolipidemic effect of fenugreek seeds and its comparison with atorvastatin on experimentally induced hyperlipidemia. J Coll Physicians Surg Pak 24: 539-542, 2014.

45. Marzouk M, Soliman AM and Omar TY: Hypoglycemic and antioxidative effects of fenugreek and termis seeds powder in streptozotocin-diabetic rats. Eur Rev Med Pharmacol Sci 17: 559-565, 2013.

46. Shivakumar A, Jashmitha BG and Dhruvaraj MR: Role of peroxidase in clinical assays: A short review. J Clin Nutr Diet 3: 2, 2017. https://doi.org/10.4172/2472-1921.100048.

47. Gaddam A, Galla C, Thummisetti S, Marikanty RK, Palanisamy UD and Rao PV: Role of fenugreek in the prevention of type 2 diabetes mellitus in prediabetes. J Diabetes Metab Disord 14: 74, 2015.

48. Herrera T, Navarro Del Hierro J, Fornari T, Reglero G and Martin D: Acid hydrolysis of saponin-rich extracts of quinoa, lentil, fenugreek and soybean to yield sapogenin-rich extracts and other bioactive compounds. J Sci Food Agric 99: 3157-3167, 2019.

49. Srinivasan K: Plant foods in the management of diabetes mellitus: Spices as beneficial antidiabetic food adjuncts. Int J Food Sci Nutr 56: 399-414, 2005.

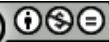

This work is licensed under a Creative Commons Attribution-NonCommercial-NoDerivatives 4.0 International (CC BY-NC-ND 4.0) License. 